\title{
Comparison of naproxen with cyclobenzaprine, oxycodone-acetaminophen, and placebo for the treatment of acute low back pain
}

\author{
Reviewed by: Michael Gottlieb, MD*; Abdoulie Njie, $\mathrm{MD}^{\dagger}$
}

\begin{abstract}
Clinical Question
Does the addition of cyclobenzaprine or oxycodone with acetaminophen to naproxen result in improved functional outcomes at one week when compared to placebo in patients with acute low back pain?

Article Chosen

Friedman B, Dym A, Davitt, M, et al. Naproxen with cyclobenzaprine, oxycodone/acetaminophen, or placebo for treating acute low back pain: a randomized clinical trial. JAMA 2015:20;314(15):1572-80.

Study Objective

The primary objective of this study was to compare functional outcomes at one week and three months after emergency department (ED) presentation for acute low back pain among patients prescribed naproxen plus one of the following: (1) oxycodone/acetaminophen; (2) cyclobenzaprine; or (3) placebo.
\end{abstract}

Keywords: low back pain, emergency department, opioid, muscle relaxant, oxycodone, cyclobenzaprine

\section{BACKGROUND}

Low back pain is a common ED presentation, resulting in $2.3 \%$ of all ED visits ${ }^{1}$. Pain outcomes and quality of life after presentations for low back pain are generally poor, with one large study demonstrating that $70 \%$ of patients had pain-related functional impairment at one week, and $48 \%$ had continued impairment at three months ${ }^{2}$. Additionally, $69 \%$ reported daily analgesic use at one week, while $46 \%$ were still using analgesics at three months ${ }^{2}$.
There are multiple medications available to treat low back pain in the acute setting. Treatment of low back pain in the ED typically involves multiple concurrent medications, with one study demonstrating that $26 \%$ of patients received both a non-steroidal anti-inflammatory drug (NSAID) and an opioid, another $26 \%$ received an NSAID and a muscle relaxant, and $16 \%$ received all three medications ${ }^{1}$. Despite the common use of these medications, the evidence for opioids in the treatment of acute low back pain is very limited $^{3}$. Additionally, existing data comparing the combination of NSAIDs plus muscle relaxants with NSAIDS plus placebo has been conflicting ${ }^{4-8}$.

\section{Population Studied}

The study enrolled adults aged 21-64 years who presented to the ED with functionally impairing, acute low back pain. Acute low back pain was described as pain of less than two weeks in duration located anatomically between the inferior border of the scapulae and superior gluteal folds. Functional impairment was defined as a score of five or greater on the Roland-Morris Disability Questionnaire (RMDQ). The RMDQ is a 24-item tool commonly used to measure low back pain and associated functional impairment, with 0 indicating no impairment and 24 indicating maximum impairment. Patients were excluded if the pain was radicular, there was direct trauma to the back within the preceding month, the duration of pain was greater than two weeks, or there was more

From the *Department of Emergency Medicine, Rush University Medical Center, Chicago, IL; and tDepartment of Emergency Medicine, Cook County (Stroger) Hospital, Chicago, IL.

Correspondence to: Michael Gottlieb, Rush University Medical Center, Department of Emergency Medicine, Chicago, IL 60612; Email: michaelgottliebmd@gmail.com 
than one episode of low back pain in the past month. Additional exclusions included pregnancy, allergy or contraindication to the study medications, chronic opioid use, inability to participate in follow-up, and prior enrollment in this study.

\section{Study Design}

This was a randomized, double-blind, placebo-control trial that enrolled 323 participants presenting to an urban teaching hospital in the United States. Patients were stratified into one of three groups using block randomization based upon the results of their baseline scores on the RMDQ. All participants received twenty 500-mg tablets of naproxen with instructions to use one tablet every 12 hours. Each of the participants also received 60 identical-appearing tablets of one of the following medications to be taken as one or two tablets every eight hours as needed: (1) oxycodone $5 \mathrm{mg}$ with acetaminophen $325 \mathrm{mg}$; (2) cyclobenzaprine $5 \mathrm{mg}$; or (3) placebo. Research personnel also provided all participants with a 10-minute educational intervention on non-pharmacologic approaches to low back pain. Patients were followed via telephone at one week and three months after hospital discharge.

\section{OUTCOMES MEASURED}

The primary outcome was improvement on the RMDQ between ED discharge and the 7-day telephone followup. A 5-point improvement was considered clinically significant. Additional outcomes assessed at seven days included severity of pain, frequency of medication use during the preceding 24 hours, patient satisfaction, length of time to return to normal activities, frequency of visits to any clinician, and adverse events. Patients were also contacted at three months after the ED visit to assess the change in their RMDQ.

\section{RESULTS}

Between April 2012 and October 2014, 323 patients were randomly assigned to one of the three groups (108 to oxycodone/acetaminophen, 108 to cyclobenzaprine, and 107 to placebo). Of these patients, 12 were lost to 7-day follow-up and 29 were lost to 3 -month follow-up. There were no major differences in baseline characteristics, although the cyclobenzaprine group had more males and the opioid group had more females. All patients had high initial RDMQ scores ranging from 19-20 out of 24, indicating substantial functional impairment at baseline.

At the 7-day follow up, there was no significant difference in the primary outcome of improvement in the RDMQ (Table 1). There were no statistically significant differences in degree of back pain in the preceding 24 hours, frequency of back pain during the preceding 24 hours, or return to normal activities. Adverse events were more common among both the oxycodone/acetaminophen group [difference: 19\% (95\% CI $=7 \%$ to $31 \%$ ), number needed to harm: 5.3 (95\% CI $=3$ to 14 )] and cyclobenzaprine group [difference: $13 \%(95 \% \mathrm{CI}=1 \%$ to $25 \%)$, number needed to harm: 7.8 ( $95 \% \mathrm{CI}=4$ to 129$)$ ] compared to placebo. The most common side effects included drowsiness, dizziness, stomach irritation, and nausea or vomiting. At the 3-month follow up, most patients had fully recovered (Table 2), but approximately $24 \%$ of participants in each of the groups still reported moderate or severe low back pain and the continued use of medications for the back pain.

Table 1. Comparison of 7-day functional disability between oxycodone/acetaminophen, cyclobenzaprine, and placebo for acute low back pain

\begin{tabular}{lc|} 
Comparison Groups & $\begin{array}{c}\text { Improvement in RMDQ between ED } \\
\text { visit and 7-day follow up }(98.3 \% \mathrm{Cl})\end{array}$ \\
\hline $\begin{array}{l}\text { Naproxen + oxycodone/ } \\
\text { acetaminophen }\end{array}$ & 11.1 (9.0 to 13.2) \\
$\begin{array}{l}\text { Naproxen }+ \\
\text { cyclobenzaprine } \\
\text { Naproxen + placebo }\end{array}$ & 10.1 (7.9 to 12.3) \\
\hline $\begin{array}{l}\text { RMDQ = Roland-Morris Disability Questionnaire; ED }=\text { emergency department; } \\
\mathrm{Cl}=\text { confidence interval. }\end{array}$ & 9.8 (7.9 to 11.7) \\
\hline
\end{tabular}

Table 2. Comparison of 3-month functional disability between oxycodone/acetaminophen, cyclobenzaprine, and placebo for acute low back pain

\begin{tabular}{|c|c|}
\hline Comparison Groups & $\begin{array}{c}\text { Mean RMDO score at 3-month } \\
\text { follow up }(95 \% \mathrm{Cl})\end{array}$ \\
\hline $\begin{array}{l}\text { Naproxen + oxycodone/ } \\
\text { acetaminophen }\end{array}$ & 4.6 (3.2 to 6.1$)$ \\
\hline $\begin{array}{l}\text { Naproxen }+ \\
\text { cyclobenzaprine }\end{array}$ & 4.5 (3.0 to 5.9$)$ \\
\hline Naproxen + placebo & 3.8 (2.6 to 5.1$)$ \\
\hline
\end{tabular}




\section{STUDY CONCLUSION}

Among patients with acute, non-traumatic, nonradicular low back pain presenting to the ED, adding cyclobenzaprine or oxycodone/acetaminophen to naproxen alone did not improve functional outcomes or pain at 1-week follow-up. These findings do not support the use of these additional medications in this setting.

\section{COMMENTARY}

Friedman et al. conducted a well-designed, randomized controlled study comparing the combination of naproxen with oxycodone/acetaminophen, cyclobenzaprine, or placebo assessing improvement in functional outcomes using a previously validated scoring tool. Based on the criteria from the Cochrane Handbook of Systematic Reviews ${ }^{9}$, this study was at low risk of bias with respect to random sequence generation, allocation concealment, blinding of participants and personnel, incomplete outcome data, selective reporting, and other bias. There was unclear risk of bias with regard to outcome assessment, as the authors do not state whether the research assistants performing follow-up phone calls were blinded to the treatment allocations.

Overall, the study demonstrated no significant difference in functional outcomes at seven days or three months. All of the patients had high baseline RMDQ scores, suggesting significant functional impairment at baseline. Additionally, the study demonstrated low rates of return visits to both the ED (1\%-3\%) and any clinician (10\%-13\%) among all three groups within the following week.

It is important to note that only $63 \%$ of the patients took the naproxen as prescribed. Additionally, only $62 \%$ of the patients took the study medication at least once per day, with $8 \%$ of the patients taking the medication only one time and $16 \%$ of the patients never taking the medication at all. Considering that $24 \%$ of the patients took the medication once or never, this may have affected the internal validity by blunting the effect difference between study groups. Therefore, it is possible that, if the medications were taken as prescribed, a difference may have been noted that was not identified in the study. However, this also increases the external validity, as patients are not always compliant with medications, and although having frequent reminders and phone calls to take medications may increase patient compliance, this approach is unrealistic in common practice. It is also unclear whether these patients may have stopped taking the medications early due to sufficient pain relief without recurrence after discharge. With regards to outcomes, the study's shortest assessment was at seven days. Given that the average return to work was three days and nearly half of the patients were pain-free at seven days, it would have been valuable to know whether there was a difference in pain relief in the first three days after ED presentation, as this may suggest a benefit for a short course of these medications. Furthermore, the study only assessed one type of opioid (oxycodone) and one type of muscle relaxant (cyclobenzaprine) given at a frequency of once every eight hours. This may not apply to other opioids or muscle relaxants or different frequencies of use. For example, oxycodone is typically prescribed every four to six hours rather than every eight hours. Taking the medication every six hours may increase pain control at the risk of increased side effects. Finally, this study was performed in a select patient population with atraumatic back pain without radicular symptoms within an urban population with typically poor follow-up. Therefore, this may not be applicable to all populations.

Of equal importance, this study also identified increased adverse effects within the cyclobenzaprine and oxycodone/acetaminophen groups, with drowsiness, dizziness, and nausea or vomiting being the most significant. While the clinical significance of these events may depend upon the individual patient, it is important to discuss potential adverse events with patients, as the number needed to harm ranged from $5.3(95 \% \mathrm{CI}=3$ to 14$)$ to $7.8(95 \% \mathrm{CI}=4$ to 129$)$.

Finally, approximately $24 \%$ of the patients still had moderate or severe low back pain at 3-month followup, suggesting that a number of patients will have prolonged pain irrespective of the acute medication given. In these patients, encouraging activity and ensuring primary care follow-up may be the most important ED interventions ${ }^{10}$.

\section{CONCLUSION}

Among patients with acute, atraumatic low back without radicular symptoms, adding oxycodone/ acetaminophen or cyclobenzaprine to naproxen alone did not improve functional outcomes or pain at seven days or three months. Additionally, there was a 
significant rate of side effects and $24 \%$ of patients still had back pain at three months. However, it is unclear if a significant difference would have been noted in the initial 48-72 hours after presentation. This study provides valuable information to consider when discussing medication regimens with patients and can inform shared decision making between provider and patient when selecting discharge prescriptions.

\section{Competing Interests: None.}

\section{REFERENCES}

1. Friedman BW, Chilstrom M, Bijur PE. Diagnostic testing and treatment of low back pain in US emergency departments. A national perspective. Spine 2010;35(24):E1406-11.

2. Friedman BW, O'Mahony S, Mulvey L, et al. One-week and 3-month outcomes after an emergency department visit for undifferentiated musculoskeletal low back pain. Ann Emerg Med 2012;59(2):128-33.e3.

3. Deyo RA, Von Korff M, Duhrkoop D. Opioids for low back pain. BM7 2015;350:g6380.
4. Berry H, Hutchinson DR. Tizanidine and ibuprofen in acute low-back pain: results of a double-blind multicentre study in general practice. 7 Int Med Res 1988;16(2):83-91.

5. Basmajian JV. Acute back pain and spasm. A controlled multicenter trial of combined analgesic and antispasm agents. Spine 1989;4:438-9.

6. Borenstein DG, Lacks S, Wiesel SW. Cyclobenzaprine and naproxen versus naproxen alone in the treatment of acute low back pain and muscle spasm. Clin Ther 1990; 12(2):125-31.

7. Childers MK, Borenstein D, Brown RL, et al. Low-dose cyclobenzaprine versus combination therapy with ibuprofen for acute neck or back pain with muscle spasm: a randomized trial. Curr Med Res Opin 2005;21(9):1485-93.

8. Pareek A, Chandurkar N, Chandanwale AS, et al. Aceclofenac-tizanidine in the treatment of acute low back pain: a double-blind, double-dummy, randomized, multicentric, comparative study against aceclofenac alone. Eur Spine 7 2009;18(12):1836-42.

9. Higgins JPT, Green S. eds. Cochrane Handbook for Systematic Reviews of Interventions, Version 5.1.0 (updated March 2011). The Cochrane Collaboration, 2011.

10. Hagen KB, Jamtvedt G, Hilde G, et al. The updated Cochrane Review of bed rest for low back pain and sciatica. Spine 2005;30(5):542-6. 